\title{
EL NUEVO MANIFIESTO CEPALINO: LA HORA DE LA IGUALDAD
}

\section{Carlos Mallorquín*}

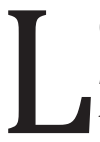
o que sigue comenta algunos aspectos sociales de La hora de la igualdad. Brechas por cerrar, caminos por abrir, presentado en Brasilia por la Comisión Económica para América Latina y el Caribe (CEPAL) durante su trigésimo tercer período de sesiones, en junio de 2010.

Desde el prólogo, firmado por la secretaria ejecutiva Alicia Bárcena, se exponen los lineamientos ético-políticos que organizan la narrativa de la trama histórica y la propuesta del documento. En los hechos se puede hablar de un análisis y perspectiva sobre la historia económica latinoamericana de las dos últimas décadas. Ciertos aspectos del panorama económico y social de América Latina y el Caribe son descritos con detenimiento.

Si bien el documento está destinado a la lectura y el conocimiento de los gobiernos de la región, se trata de un texto valiente que intenta romper con mucho del vocabulario «técnico» de los documentos de las organizaciones internacionales:

La aguda desigualdad que secularmente ha recorrido América latina y el Caribe hunde sus raíces en la historia. Se remonta a la radical negación de derechos en función de categorías raciales y estamentales que confinó a gran parte de la población del continente a la esclavitud, el sometimiento y la expropiación de recursos. En la vida republicana los privilegios siguieron reproduciéndose de otras diversas maneras, que mantuvieron asimetrías en cuanto a derechos y condiciones de vida. Finalmente, el patrón de desarrollo y modernización perpetuó las brechas socioeconómicas basadas en el origen racial y étnico, el género y

* Profesor-investigador del Doctorado en Estudios del Desarrollo de la Universidad Autónoma de Zacatecas. 
la clase social. La estructura productiva y las oportunidades educativas consagraron patrones de reproducción de la desigualdad y, en gran medida, lo siguen haciendo (CEPAL, 2010: 185).

Como dice Bárcena, el diagnóstico y las propuestas tienen como punto de referencia central recuperar la importancia del «valor de la igualdad» y la «solidaridad»:

Porque creemos interpretar un reclamo histórico largamente sostenido y postergado en las sociedades latinoamericanas y caribeñas. A partir de este reclamo se han ensayado, con mayor o menor fortuna, revoluciones y reformas, modelos de gobierno y de política, movimientos populares, acuerdos entre grupos y demandas de los más diversos actores. Además, provee el punto de partida ético-político para universalizar prestaciones (no solo en materia de acceso), sino también para reducir brechas en la calidad y las trayectorias. La igualdad constituye el marco normativo para el pacto fiscal y el pacto social del que surge el carácter vinculante de los derechos ratificados y sus implicancias en cuanto a progresividad y redistribución (CEPAL, 2010:13). / La igualdad de derechos no erosiona la meritocracia ni desincentiva los esfuerzos individuales. Por el contrario, promueve un sentido de pertenencia que motiva a los agentes a contribuir al bien común y al progreso económico, pues redunda en derechos más efectivos y en una mayor protección para cada persona. Supone la participación de una gama más amplia de actores que aportan al bien común. (CEPAL, 2010:12).

Si bien el texto concentra gran parte de su relato en describir las graves diferencias («brechas», como gusta decir el texto) entre distintos sectores, las asimetrías sociales y económicas, entre sectores y los agentes productivos, así como las consecuencias para la organización espacial territorial de los países y sus regiones, otorga una amplio lugar para disertar sobre otros fenómenos sociales y políticos que superan con mucho las capacidades de los gobiernos latinoamericanos: por un lado, el cuidado del medio ambiente plateando políticas económicas cuya reducción en la emisión de carbono debe ser su punto de partida y, por el otro lado, la reconstrucción y 
reorganización de una arquitectura financiera mundial multilateral. Problemática que confiesa fue escrita bajo el influjo de la elección de Barack Obama como presidente de Estados Unidos y su promesa de reformar la gobernabilidad financiera local y mundial, aspecto que hoy sabemos sigue sin atenderse plenamente. Sin embargo, gran parte del texto contiene referencias a trabajos previos de CEPAL o sus colaboradores sobre importantes experimentos teóricos y políticos (véase, CEPAL, 2007, 2005, 2009 y 2007).

El desastre y desorden financiero generado en el «coloso del norte», así como sus graves consecuencias mundiales a partir del 2008, facilitaron la elaboración de una crítica a los insostenibles fundamentos del sistema financiero estadounidense e internacional y propinar una última estocada al mito de la globalización y el «consenso de Washington».

De hecho, el relato dice que antes del desastre financiero, las economías de la región y la tendencia mundial del crecimiento iban casi por buen camino:

En la segunda mitad de 2009 se observaron señales positivas en las economías de la región. La producción industrial y las exportaciones comenzaron a recuperarse, al tiempo que el aumento del nivel de actividad global y de los volúmenes de comercio internacional impulsó la demanda de productos básicos (CEPAL, 2010, 21).

El documento presenta una gran diversidad de estadísticas y cuadros, estimaciones y modelos de simulación, que apoyan gran parte de sus propuestas y diagnósticos para cambiar la política económica que dominó a la región en los últimos 20 años. Pero el aspecto central es la reflexión y visión sobre los aspectos que fomentan las transformaciones sociales y la evolución de las sociedades de la región. En otras palabras, la manera en que se pueden reducir las «diferencias» (o «brechas») entre sectores, ramas productivas, regiones e ingresos de los agentes productivos a consecuencia de la «heterogeneidad estructural». El elemento central puede verse en el tercer capítulo: «Heterogeneidad estructural y 
brechas de productividad: de la fragmentación a la convergencia materia de productividad». Dicho aspecto estructural de la economía engloba:

Las brechas sociales no pueden explicarse sin entender la desigualdad en la calidad y productividad de los puestos de trabajo en y entre los distintos sectores de la actividad económica, la que se proyecta en rendimientos muy desiguales entre los trabajadores, el capital y el trabajo (...) la brecha interna, o sea, las notorias diferencias de productividad que existen entre los distintos sectores y dentro de cada uno de ellos, así como entre las empresas de cada país, (...) que son muy superiores a las que se observan en los países desarrollados. Esto se denomina heterogeneidad estructural y denota marcadas asimetrías entre segmentos de empresas y trabajadores, que se combinan con la concentración del empleo en estratos de muy baja productividad relativa (...) Heterogeneidad estructural y brechas de productividad: de la fragmentación a la convergencia materia de productividad (...) rezago relativo, o brecha externa, que refleja las asimetrías en las capacidades tecnológicas de la región con respecto a la frontera internacional (...) economías desarrolladas innovan y difunden tecnología (...) supera la rapidez con que los países de América Latina y el Caribe (CEPAL, 2010: 91).

Como se pudo observar, es un fenómeno que parece definirse como transitando entre nociones relacionadas con asimetrías de poder en las relaciones sociales que constituyen distintos sectores y agentes productivos, y las diferencias productivas y tecnológicas sectoriales o inter e intrasectoriales. Volveremos más adelante para intentar radicalizar un poco más este aspecto. Especialmente porque la idea de diferencias o brechas supone que la estrategia y el proceso evolutivo tienen como meta algo así como una «convergencia».

Antes, cabe recordar que el documento no rehúye argumento y espacio para proponer formas de lidiar con un medio ambiente internacional que genera precios y flujos de capitales procíclicos en la región que limitarían una política de crecimiento y de transformación estructural consistente para la planeación del horizonte a 
largo plazo de los agentes productivos, lo cual es objeto del capítulo segundo: «Política macroeconómica para el desarrollo: de la experiencia adquirida a la inflexión necesaria»:

Durante los períodos de auge, tiende a contagiarse el exceso de optimismo que impulsa al alza los precios de los activos - y crea burbujas (...) El comportamiento procíclico de las instituciones calificadoras de riesgo profundizó el desequilibrio por la vía de las expectativas de los agentes (...) las instituciones calificadoras de riesgo-, con sus evaluaciones hayan tendido a alimentar los desequilibrios (...) El comportamiento procíclico de los flujos se transmite al tipo de cambio real en el sentido de que un auge a menudo ha provocado fuertes revaluaciones cambiarias, que en reiteradas ocasiones propiciaron desequilibrios en la cuenta corriente (...) controlar la transmisión de la volatilidad financiera globalizada En economías con mercados imperfectos e incompletos como suelen serlo los de la región-, los choques provocan ajustes en los precios y en el número de bienes producidos y comercializados, que se añaden a los efectos de la heterogeneidad estructural (...) En economías con mercados imperfectos e incompletos - como suelen serlo los de la región-, los choques provocan ajustes en los precios y en el número de bienes producidos y comercializados, que se añaden a los efectos de la heterogeneidad estructural (CEPAL, 20010: 64-65).

Ocasionalmente, en el cuarto capítulo («El lugar importa: disparidades y convergencias territoriales»), las diferencias o brechas entre regiones y zonas geográficas aparecen representadas bajo el vocablo de «heterogeneidad»:

La fuerte heterogeneidad de las entidades territoriales subnacionales de América Latina se expresa en altos niveles de concentración espacial y en las persistentes disparidades, entendidas como desigualdades en la distribución territorial de la riqueza (CEPAL, 2010: 132).

Se demuestra la manera en que América Latina, en comparación, por ejemplo con los países de la Organización para la Cooperación y el Desarrollo Económico (OCDE), presenta ciertos espacios geográficos 
o regiones donde se generan algunas aglomeraciones y sinergias productivas que concentran los frutos del progreso técnico y marginan a otras. En ciertas zonas geográficas, el fruto del progreso técnico, sus ingresos, así como las asimetrías, se presentan con toda su violencia: muchas de las necesidades insatisfechas básicas y sus círculos viciosos (ausencia de acceso a educación, de cuidado de los mayores y de empleos) se concentran en determinados espacios y regiones: necesidades que caen, con toda su crudeza, en los sectores marginados, jóvenes, infantes, mayores de edad y grupos étnicos:

las disparidades de América Latina siguen siendo altas y no han experimentado un cambio significativo en los últimos dos decenios (...) la alta concentración espacial de la población y de la actividad económica de América Latina se acompaña de muy fuertes disparidades territoriales - brechas en el PIB per capita territorial一, mientras que en los países de la OCDE los índices de concentración no son tan altos ni están asociados a la existencia de disparidades (...) la concentración y las disparidades han ido de la mano y han provocado una situación de inequidad territorial que reclama adecuadas respuestas de política pública (...) desigualdades económicas territoriales.. y las carencias, las necesidades básicas insatisfechas. Se tomó como referencia la población menor de 18 años y sus privaciones (...) materiales de construcción de la vivienda, hacinamiento, acceso al agua potable, saneamiento, educación de los niños y presencia de medios de comunicación o información (...) muy fuerte concentración de los habitantes menores de 18 años con privaciones graves, sobre todo en las regiones andina y amazónica, que abarcan vastos territorios donde entre el $88,8 \%$ y el 100\% de la población se encuentra en estas condiciones (...) En México y Centroamérica la distribución territorial de la población con privaciones graves muestra una mayor dispersión de los territorios menos favorecidos (...) al igual que en las regiones andina y amazónica, se observa que las zonas más críticas tienden a ubicarse donde hay una alta incidencia de la población indígena, como el sur de México y Guatemala (CEPAL, 2010: 138).

El bajo nivel del impuesto predial como fuente de recursos locales para generar proyectos de políticas locales de desarrollo están limitados. Por lo tanto, casi no tiene sentido intentar estrategias y 
políticas de «abajo hacia arriba», lo cual impone dar mayor atención a las transferencias de recursos interregionales de «arriba hacia abajo».

Este aspecto del documento debe tomarse en cuenta en la evaluación de las políticas de crecimiento propuestas, porque se pone gran énfasis en la importancia de la participación social, en los «pactos sociales» y fundamentalmente las pequeñas y medianas empresas (Pymes). Ello explica la idea de generar «fondos de cohesión territorial».

En la narrativa del texto, la importancia, limitaciones y consecuencias de la descentralización da inicio a la aparición de la figura del Estado en el vocabulario del documento: retorna casi como el actor crucial, proactivo e ineludible, para generar una política de desarrollo, problemática que se desarrolla ampliamente en el último capítulo: «Estado, Política, fiscalidad y pactos sociales: una ecuación por construir».

No menos importante es la insistencia del texto en pensar las cadenas que reproducen la pobreza intergeneracional, y por tanto la importancia de construir ámbitos para el cuidado de los miembros del hogar y reducir la jornada de trabajo de las mujeres y la igualdad de las poblaciones dependientes de esos hogares a través de la inversión social:

muchas mujeres pasaran a ejercer doble jornada laboral — de trabajo remunerado y de cuidado de los miembros del hogar (...) no lograran insertarse oportunamente en el empleo debido a su alta carga de cuidado en el hogar (...) Esto no ha hecho sino reforzar la desigualdad ya que en los hogares de menores ingresos la dificultad de delegar las tareas de cuidado reduce la posibilidad de incorporar un aportante adicional de recursos monetarios (CEPAL, 2010: 162).

Aspectos cruciales de la desigualdad y la generación de la pobreza, ya sea por razones de pertenencia social y ubicación geográfica, se discuten ampliamente en la capítulo quinto: «La dinámica del empleo y la institucionalidad laboral como clave de la igualdad de oportunidades y la inclusión social». Como las «fuerzas del 
mercado» no generan empleos, ni garantizan la absorción de la población en edad de trabajar de manera automática, las políticas públicas deberán coadyuvar a dicho proceso. La reflexión sobre la reducción de la pobreza incluye políticas de apoyo a los desempleados, capacitación laboral, «flexibilidad laboral»y defensa del empleo. Cierta seguridad económica durante el desempleo genera a largo plazo la inclusión y formación de recursos capacitados para acrecentar la transformación productiva de las empresas. El «entorno institucional» (CEPAL, 2010: 178) debe transformarse apoyándose en algún mecanismo de ingreso durante el desempleo que sea independiente de las transferencias individuales, lo cual nuevamente pone el acento en las contribuciones universales y la importancia del pacto fiscal a nivel nacional (ver capítulo VII).

En el sexto capítulo: «Las brechas sociales por cerrar», se destaca las discusiones y evolución de los índices de pobreza de la región:

La disparidad distributiva que caracteriza a los países de América Latina puede observarse al comparar la relación de ingresos entre el decil más rico y los cuatro deciles más pobres, y entre el quinto quintil (es decir, el 20\% de los hogares situados en el extremo superior de la distribución) y el primer quintil. De acuerdo con el primero de estos índices, el ingreso medio por persona delos hogares ubicados en el décimo decil supera alrededor de 17 veces al del 40\% de los hogares más pobres. Esta relación es altamente variable de un país a otro. Va desde alrededor de nueve veces en la República Bolivariana de Venezuela y el Uruguay, hasta 25 veces en Colombia (datos de 2005). Por su parte, el ingreso per capita del quintil más rico supera, en promedio, 19 veces el del más pobre, con un rango que va desde menos de 10 veces (en los mismos países indicados antes) a 33 veces en Honduras (185-186)./ El período 2003 a 2008, en cambio, no solo se caracterizó por un crecimiento económico sostenido, sino por una tendencia, leve pero evidente, hacia una menor concentración del ingreso. El índice de Gini cayó un $5 \%$ a nivel regional con respecto al valor de 2002, empujado sobre todo por las disminuciones experimentadas por la Argentina (área metropolitana), el Estado Plurinacional de Bolivia (área urbana), Panamá (área urbana) y la República Bolivariana de Venezuela, 
todas superiores al 10\%. También el Brasil, Chile, el Ecuador (área urbana), Nicaragua y el Paraguay (área metropolitana) registraron reducciones importantes del indicador, del 7\% o más (...) La evolución positiva de la distribución del ingreso en América Latina en el sexenio 2003-2008 estuvo ligada principalmente a la dinámica del mercado de trabajo (...) El empleo se expandió a un ritmo que sobrepasó al de la oferta laboral y todos los grupos de ingreso se beneficiaron del incremento en la tasa de ocupación, por lo que este factor no fue decisivo en la reducción de las brechas entre quintiles (CEPAL, 2010: 185-186,188).

Vale la pena señalar la consideración de la evolución positiva de la economía regional, que obviamente se convertirá en un tema controversial en años posteriores. A lo largo del documento, el sexenio 2003-2008 se presenta como un período benigno para ciertas variables sociales, que subsecuentemente se detiene y observa una inflexión a la baja ${ }^{1}$ con el devenir del desastre financiero estadounidense. Sin embargo, el documento presenta una esperanza, y tal vez ilusión, fuera de lugar, respecto a la posibilidad de que algunos países de la región controlen la volatilidad de los capitales a través de algunos mecanismos de control (CEPAL: 2010: 86-89).

Finalmente, creemos que la ambigüedad de la noción de heterogeneidad, ya sea que se asuma como un fenómeno que suponga una diversidad tecnológica entre sectores y agentes productivos que debe superarse o la idea de que se origina en la organización social y asimetrías de poder de los agentes productivos en y entre las unidades productivas, puede superarse si lo pensamos en términos de poder. La asimetría de poder es la que genera esa «heterogeneidad», que a su vez limita las transformaciones estructurales, por eso se habla de «reformas estructurales» en ámbitos sociales diversos, el de la tierra, formas de producción, salarios mínimos, etcétera. No es sencillamente la inducción de un proceso de «industrialización». Esto implica que la «productividad» tiene mucho que ver en la forma en que agentes (productivos o naciones: China castiga a varios sectores para ocupar un espacio en el 
comercio internacional) pueden imponer precios o defenderlos. La heterogeneidad debe explicarse local o internacionalmente como producto de relaciones del «empoderamiento» o su relativa ausencia en y entre ciertas unidades de producción: las formas de posesión en separación de algunas de sus condiciones de existencia. Son formas de posesión en separación porque representan la desarticulación de las unidades productivas, entre sí y sus respectivas condiciones de existencia, donde los elementos que explicarían las asimetrías de poder están en «posesión» de otras unidades: créditos, establecimientos de contratos, imposición de precios, mano de obra mercantil (ver Mallorquín, 2011).

\section{REFERENCIAS}

CEPAL (2010), La hora de la igualdad. Brechas por cerrar, caminos por abrir, Santiado de Chile, 2010.

(2005), Structural Heterogeneity, Technological Asymmetries and Growth in Latin America, Santiago de Chile. (2007) Cohesión social, Santiago de Chile. (2007b) Progreso Técnico y cambio estructural en América Latina, Santiago de Chile. (2009) Economía y territorio en América Latina (2009)

MALLORQuín, Carlos (2012), «Repensando la noción de "heterogeneidad" en la concepción estructuralista latinoamericana», en Humberto Márquez; Roberto Soto y Edgar Zayago (coords.), Visiones del desarrollo, México, en prensa. 